\title{
Garre's Osteomyelitis of the Mandible: Report of 2 Cases
}

\author{
Ali Mohammed Makrami ${ }^{1}$, Afaf Ali Hakami ${ }^{2}$, Ahlam Ahmed Alhazmi ${ }^{3}$, Ahlam Ahmed Shafei ${ }^{3}$, Mahasin Ahmed Alnemi ${ }^{3}$, \\ Samsheer Kannambra Mohammed $\mathrm{Ali}^{3}$, Fareedi Mukram $\mathrm{Ali}^{3 *}$ \\ ${ }^{1}$ Department of Oral and Maxillofacial Surgery, Prince Mohammed Bin Nasser Hospital, Ministry of Health, Jazan, \\ Saudi Arabia; ${ }^{2}$ Ministry of Health, Jazan, Saudi Arabia; ${ }^{3}$ College of Dentistry, Jazan University, Jazan, Saudi Arabia
}

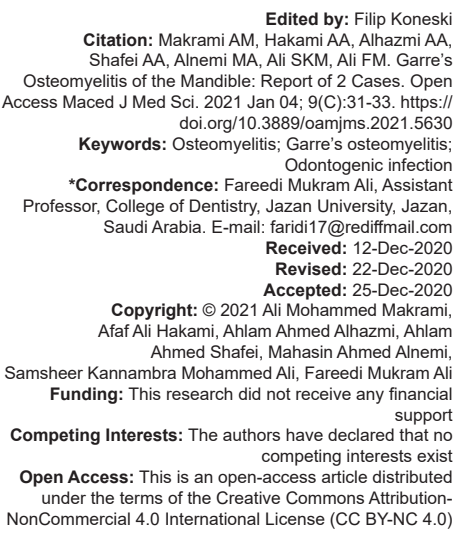

Edited by: Filip Konesk Citation: Makrami AM, Hakami AA, Alhazmi AA, Shafei AA, Alnemi MA, Ali SKM, Ali FM. Garre's Osteomyelitis of the Mandible: Report of 2 Cases. Open Access Maced J Med Sci. 2021 Jan 04; 9(C):31-33. https:// doi.org/10.3889/oamjms.2021.5630 Keywords: Osteomyelitis; Garre's osteomyelitis; *Correspondence: Fareedi Mukram Ali infection Professor College of Dentistry, Jazan University, Jazan, Saudi Arabia. E-mail: faridi17@rediffmail.com Received: $12-$ Dec-2020 Revised: 22-Dec-2020 Accepted: 25-Dec-2020 Copyright: @ 2021 Ali Mohammed Makram Afaf Ali Hakami, Ahlam Ahmed Alhazmi, Ahlam Ahmed Shafei, Mahasin Ahmed Alnem amsheer Kannambra Mohammed Ali, Fareedi Mukram Ail Funding: This research did not receive any financia Competing Interests: The authors have declared that no Open Access: This is an open-access article distributed under the terms of the Creative Commons AtributionNonCommercial 4.0 International License (CC BY-NC 4.0)

\section{Abstract}

BACKGROUND: Garre's osteomyelitis is a rare type of chronic osteomyelitis that mainly affects children and young adults. This disease is commonly associated with an odontogenic infection resulting from dental caries.

CASE REPORTS: This article describes two case reports of young boys with Garre's osteomyelitis of mandible caused by odontogenic infection.

RESULTS: The cases were managed by extraction followed by antibiotics and the healing was achieved uneventfully.

\section{Introduction}

Osteomyelitis is an inflammatory process of bone and bone marrow caused by an infectious organism(s) which results in local bone destruction, apposition of new bone, and necrosis. Osteomyelitis can be either acute or chronic [1], [2], [3]. Garre's osteomyelitis is a rare type of chronic osteomyelitis, which was first described by Carl Garre in 1893 [4]. It present as a chronic non-suppurative sclerotic bone inflammation that affects children and adolescents, distinguished by a rigid bony swelling at the periphery of the jaw [5], [6], [7], [8]. It was reported only in long bone in the tibia until Berger described a case involving the mandible in 1948 [9].

Periapical infection is the most common cause of Garre's osteomyelitis and results from an infection of low virulence, such as dental caries, dental eruption, mild periodontitis, or previous dental extraction in the lesion area [8], [10].

The mandible is more affected than the maxilla and mostly seen at the mandibular first molar region [5], [7], [8], [10], [11]. Clinically, Garre's osteomyelitis producing facial asymmetry results in a hard swelling over the jaw, with little or no pain [4],
[7], [8], [12], [13]. Radiographically, it has an "onion skin" appearance characterized by the presence of lamellae of newly formed subperiosteal bone overlying the cortex [10].

We aimed to present the extraoral, radiographic findings, and post-operative results of two patients diagnosed with Garre's osteomyelitis.

\section{Case Reports}

\section{Case 1}

A 13-year-old Saudi male, who is otherwise medically fit, presented to the oral surgery department at Gazan Dental Centre in July 2017. He was complaining of a slowly progressive painless swelling on the left body of the mandible (Figure 1a).

Extraoral examination revealed facial asymmetry caused by non-tender bony hard mass at the left side of mandible. The skin color appeared to be normal and there was no rise in temperature on that area, the lymph node was palpable but not tender, and a normal mouth opening was present. 
Intraoral examination revealed a hard and nontender buccal swelling in relation to a badly decayed mandibular first molar of the left side. The tooth was non-tender to percussion and there were no signs of any sinus tracts.

Radiographic investigations, namely orthopantomogram (OPG) and intraoral periapical X-ray, showed a well-demarcated periapical radiolucency in relation to a mandibular first molar of the left side. Conebeam computed tomography system (CBCT) showed typical onion peel appearance (Figure $1 \mathrm{~b}$ and $\mathrm{c}$ ).

Diagnosis of Garre's osteomyelitis was made and subsequent to endodontics consultation, the offending tooth was removed and curettage was performed and Augmentin $625 \mathrm{mg}$ b.i.d for 5 days was prescribed. The case was followed up for 2 weeks and at the end of 2 months.

On examination, the swelling regressed completely and his facial symmetry was restored back to normal (Figure 1d).

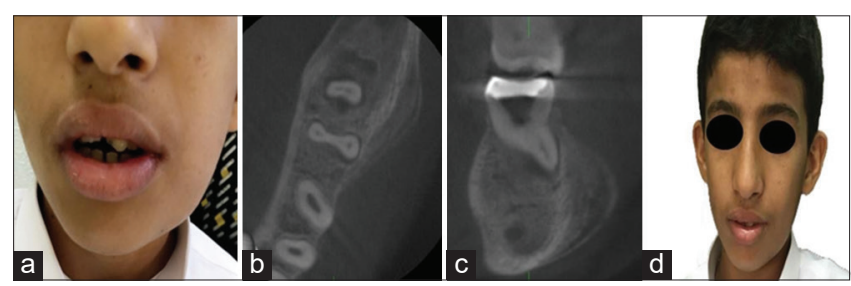

Figure 1: (a) Pre-operative photographs of the patient showing facial asymmetry and presence of non-painful swelling in the mandibular left posterior region. (b) Computed tomography showing radiopaque deposition mixed with radiolucency at the left mandibular buccal border. (c) Computed tomography showing radiopaque deposition mixed with radiolucency at the left mandibular lower border. (d) Follow-up of the patient demonstrating ameliorated facial appearance

\section{Case 2}

A 16-year-old Saudi male, who is otherwise medically fit, presented to oral surgery outpatient department in Gizan Dental Centre in July 2017.

He was complaining of a slowly progressive painless swelling on the lower right body of the mandible for 2 months. Upon eliciting history, it was noted that there were recurrent episodes of abscess formation in relation to a badly decayed molar tooth on the right side of the mandible, intermittently for 2 years (Figure 2a).

Extraoral examination revealed facial asymmetry on the right side, with the swelling extending almost $2 \mathrm{~cm}$ in the region of mandibular first and second molar of the right side. The skin color appeared to be normal and there was no rise in temperature on that area. The submandibular lymph nodes were palpable without tenderness. The mouth opening was also normal.

Intraoral examination revealed a hard and non-tender swelling in relation to a badly decayed right mandibular first molar.
The tooth was non-tender to percussion and there were no signs of any sinus tracts in relation to the same.

OPG and periapical X-ray showed periapical radiolucency in relation to mandibular second molar of the right side with a dense radiopaque band surrounding the lesion. CBCT showed a typical onion peel appearance (Figure $2 b$ ).

Diagnosis of Garre's osteomyelitis was made and subsequent to endodontics consultation, the offending tooth was removed, and curettage was performed and Augmentin $625 \mathrm{mg}$ b.i.d for 5 days was prescribed. The case was followed up for 2 weeks and at the end of 2 months.

After 2 months, the swelling was regressed completely and his facial symmetry was restored back to normalcy (Figure 2c). Histopathological examination had confirmed the diagnosis of osteomyelitis (Figure 2d).

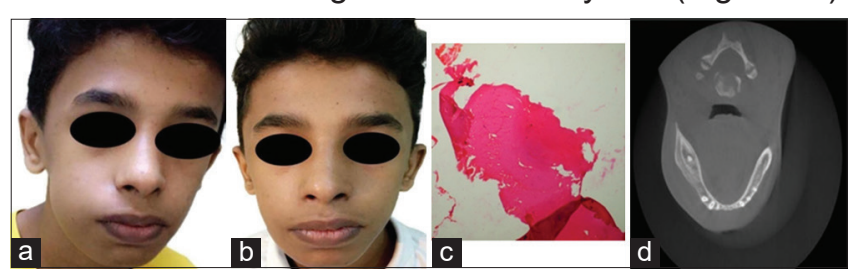

Figure 2: (a) Initial photograph showing facial asymmetry, nonpainful swelling. (b) Computed tomography showing radiopaque deposition mixed with radiolucence at the right mandibular lower border. (c) Follow-up of the patient demonstrating ameliorated facial appearance. (d) Histopathological picture showing the presence of non-vital bone

\section{Discussion}

Garre's osteomyelitis is a localized periosteal thickening, starting from the spongiosa layer of the jaw and extending into the periosteum and end by stimulating bone formation. However, for this pathological condition to occur, the balance between the virulent bacteria and oral flora must be impaired, while the periosteal osteoblastic activity must also be high [1], [4].

In atypical cases with a negative history of chronic abscesses, deep carious lesions, or trauma to the area, bone biopsies are recommended to rule out several disease entities. These include the following [14]:

1. Infantile cortical hyperostosis or Caffey's disease: This is a syndrome arising during the first 6 months of life with unknown etiology and affecting mostly the mandible with the manifestation of a peripheral bony swelling. This disease runs a benign course and subsides without treatment in several months

2. Ewing's sarcoma: A rare malignant neoplasm occurring predominantly in children, which produces layers of new subperiosteal bone on 
radiographs producing a "bony tumor" when affecting the mandible. Radical surgery with radiotherapy is recommended with a poor prognosis

3. Osteogenic sarcoma: A sclerosing form exhibits the typical sun-rays appearance of osteosarcoma on X-rays, mostly affects males between 10 and 25 years of age, and produces facial asymmetry when the mandible is involved. It is highly malignant and radical surgery is the recommended treatment and the prognosis is poor.

Our two cases showed obvious clinical and radiographic features; therefore, a biopsy was not done during the diagnosis of Garre's osteomyelitis [8], [11].

The two cases presented the same characteristic features as those reviewed in the literature like the presence of a bony hard swelling lateral to the inferior border of the mandible, producing facial asymmetry. Long-standing carious lesion or other odontogenic infection often brought the patient to seek treatment rather than the pain. Within 6-8 months, the lesions usually regress with subsequent bone remodeling [15], [16], [17], [18].

\section{Conclusion}

This type of lesion often comes in a neglected patient with low family educational level. Early health education must be given to the patient regarding the possible sequelae of the infection and the patient should be motivated for the early treatment.

\section{References}

1. LewDP,WaldvogelFA. Osteomyelitis.NEngIJMed.1997;336(14):9991007. https://doi.org/10.1056/nejm199704033361406 PMid:9077380

2. Rosenberg AE. Bones, joints, and soft-tissue tumors. In: Kumar V, Abbas AK, Fausto N, Aster JC, editors. Robbins and Cotran Pathologic Basis of Disease. $8^{\text {th }}$ ed. Philadelphia, PA: Saunders Elsevier; 2010. p. 1205-56. https://doi.org/10.1016/ b978-1-4377-0792-2.50031-6

3. Mouzopoulos G, Kanakaris NK, Kontakis G, Obakponovwe O, Townsend R, Giannoudis PV. Management of bone infections in adults: The surgeon's and microbiologist's perspectives.

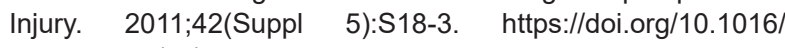
s0020-1383(11)70128-0

\section{PMid:22196905}

4. Jayasenthil A, Aparna PV, Balagopal S. Non-surgical endodontic management of Garre's osteomyelitis: A case report. $\mathrm{Br}$ J Med Med Res. 2015;9(3):1-4. https://doi.org/10.9734/ bjmmr/2015/17772

5. Karjodkar FR. Textbook of Dental and Maxillofacial Radiology. $2^{\text {nd }}$ ed. Panama: Jaypee Brothers Medical Publishers; 2009.

6. Çelenk P, Akgül HM. Garre's osteomyelitis (a case report). J Ondokuz Mayis Univ Dent Fac. 2000;3:29-31.

7. Nakano H, Miki T, Aota K, Sumi T, Matsumoto K, Yura Y. Garré's osteomyelitis of the mandible caused by an infected wisdom tooth. Oral Sci Int. 2008;5(2):150-4. https://doi.org/10.1016/ s1348-8643(08)80021-3

8. Suma R, Vinay C, Shashikanth MC, Subba Reddy VV. Garre's sclerosing osteomyelitis. J Indian Soc Pedod Prev Dent. 2007;25:30-3.

PMid:17921638

9. Berger A. Perimandibular ossification of possible traumatic origin; report of case. J Oral Surg (Chic). 1948;6(4):353-6.

PMid: 18884510

10. Kannan SK, Sandhya G, Selvarani R. Periostitis ossificans (Garrè's osteomyelitis) radiographic study of two cases. Int J Paediatr Dent. 2006;16(1):59-64. https://doi. org/10.1111/j.1365-263x.2006.00630.x PMid:16364095

11. Gonçalves M, Pinto Oliveira D, Oliveira Oya E, Gonçalves A. Garre's osteomyelitis associated with a fistula: A case report. J Clin Pediatr Dent. 2002;26(3):311-3. https://doi.org/10.17796/ jcpd.26.3.v65535482m037304 PMid:11990057

12. Erişen M, Bayar OF, Ak G. Garre osteomyelitis: A case report. J Dent Fac Atatürk Univ. 2014;9:49-53.

13. Brazão-Silva MT, Pinheiro TN. The so-called Garrè's osteomyelitis of jaws and the pivotal utility of computed tomography scan. Contemp Clin Dent. 2017;8(4):645-6. https:// doi.org/10.4103/ccd.ccd_304_17

14. Bhaskar SN. Synopsis of Oral Pathology. Ch. 12. Saint Louis: C.V. Mosby Company; 1977. p. 334-5.

15. Ellis D, Winslow J, Indovina A. Garré's osteomyelitis of the mandible. Report of a case. Oral Surg Oral Med Oral Pathol. 1977;44(2):183-9. https://doi. org/10.1016/0030-4220(77)90266-3 PMid:268570

16. Shafer WG, Hine MK, Levy BM. Text Book of Oral Pathology. Ch. 8. Philadelphia, PA: W.B. Saunders Company; 1974. p. 458-41.

17. Stafne EC. Oral Roentgenographic Diagnosis. Ch. 7 . Philadelphia, PA: W.B. Saunders Company; 1975. p. 84-5.

18. Pell GJ, Shafer WG, Gregory GT, Ping RS, Spear LB. Garre's osteomyelitis of the mandible; report of a case. J Oral Surg (Chic). 1955;13:248-52.

PMid:14392543 